\title{
In situ Grazing Incidence Small Angle X-ray Scattering on Roll-To-Roll Coating of Organic Solar Cells with Laboratory X-ray Instrumentation
}

\author{
Michael Korning Sørensen ${ }^{1}$, Moises Espindola Rodriguez ${ }^{1}$, Marcial Fernández Castro ${ }^{1}$, Ashwin Nambi ${ }^{1}$, Luise Theil \\ Kuhn ${ }^{1}$, Jens Wenzel Andreasen ${ }^{1}$ \\ ${ }^{1}$ Department of Energy Conversion and Storage, Technical University of Denmark
}

\section{Corresponding Author}

Jens Wenzel Andreasen

jewa@dtu.dk

\section{Citation}

Korning Sørensen, M., Espindola

Rodriguez, M., Castro, M.F., Nambi, A.,

Kuhn, L.T., Andreasen, J.W. In situ

Grazing Incidence Small Angle X-ray

Scattering on Roll-To-Roll Coating of

Organic Solar Cells with Laboratory X-

ray Instrumentation. J. Vis. Exp. (169),

e61374, doi:10.3791/61374 (2021).

\section{Date Published}

March 2, 2021

DOI

$10.3791 / 61374$

\section{Abstract}

We present an in-house, in situ Grazing Incidence Small Angle X-ray Scattering (GISAXS) experiment, developed to probe the drying kinetics of roll-to-roll slot-die coating of the active layer in organic photovoltaics (OPVs), during deposition. For this demonstration, the focus is on the combination of P3HT:O-IDTBR and P3HT:EHIDTBR, which have different drying kinetics and device performance, despite their chemical structure only varying slightly by the sidechain of the small molecule acceptor. This article provides a step-by-step guide to perform an in situ GISAXS experiment and demonstrates how to analyze and interpret the results. Usually, performing this type of in situ X-ray experiments to investigate the drying kinetics of the active layer in OPVs relies on access to synchrotrons. However, by using and further developing the method described in this paper, it is possible to perform experiments with a coarse temporal and spatial resolution, on a day-to-day basis to gain fundamental insight in the morphology of drying inks.

URL

jove.com/video/61374

\section{Introduction}

Organic photovoltaics (OPVs) represents one of the most promising emerging solar cell technologies. OPVs can enable large-scale production of a cost-effective renewable energy source based on nontoxic materials with remarkable short energy payback times ${ }^{1}$. The photoactive part in OPVs is an approximately $300-400 \mathrm{~nm}$ thick layer of conductive polymers and molecules, which can be printed at a rate of several meters per minute by roll-to-roll coating techniques ${ }^{1}$. This thin-film technology is flexible, colorful, and lightweight, which opens paths for new solar energy markets, such as Internetof-Things, building integration, decorative installations and fast installation/uninstallation at very large scale $\mathrm{scos}^{2,3,4,5}$. Furthermore, OPVs consist solely of abundant and nontoxic elements, which make them both cheap to produce and 
recycle. Therefore, this technology is receiving increasing attention from industry and academia. Tremendous efforts have been made to optimize each layer in the complete stack that constitutes the organic solar cell, and a lot of theoretical and experimental research has been done to understand the underlying physics of OPVs ${ }^{6,7,8}$. The enormous interest in the technology has pushed the field to its current state where champion devices fabricated in laboratories are exceeding $18 \%$ efficiency ${ }^{9}$. However, upscaling the fabrication (i.e., moving from spin-coating on rigid substrates to scalable deposition on flexible substrates) is accompanied by significant losses in efficiency ${ }^{10}$. Bridging this gap is thus paramount for OPVs to become competitive with other commercially available thin-film solar cell technologies.

OPV is a thin-film technology that consists of several functional layers. In this demonstration, the focus is solely on the photoactive layer. This layer is particularly important, as this is where the photons are absorbed, and the photocurrent is generated. Typically, the photoactive layer consists of at least two constituents, namely a donor and an acceptor. Here, the focus is on the donor polymer P3HT in combination with either O-IDTBR or EH:IDTBR as the acceptor ${ }^{11}$, with the chemical formulas as shown in Figure 1. The optimal design of the photoactive layer is described as a bulk heterojunction $(\mathrm{BHJ})$, where the compounds are intermixed throughout the device, as shown in Figure 2. The BHJ is obtained by slotdie coating an ink consisting of the donor and the acceptor in solution ${ }^{10}$. While coating the wet ink onto the substrate, the solvent molecules evaporate, which leaves the donor and acceptor in an intermixed state. The distribution of donor/acceptor with respect to phase separation, orientation, ordering, and size distribution, is commonly referred to as the morphology of the BHJ. The morphology of the active layer plays a significant role in the solar cell performance due to the nature of the working principle ${ }^{4,12}$. The working principle is illustrated in Figure 2 and can be described in four steps: First, an incoming photon is absorbed and excites an electron from the highest occupied molecular orbital (HOMO) to the lowest unoccupied molecular orbital (LUMO). The hole (a vacant state in the HOMO) and the excited electron are bound together. This bound electron-hole-pair is referred to as an exciton. Second, the exciton is free to move around, and the approximate mean free path before recombination is $20 \mathrm{~nm}^{6}$. Third, when the exciton is near an interface between donor and acceptor, it is energetically favorable to dissociate into a free electron in the LUMO of the acceptor and a free hole in the HOMO of the donor. Fourth, if the device is connected to a circuit, charges will thereby be transported to the anode and cathode. To improve the functionality of OPVs, the morphology must be optimized to accommodate each of the four steps to ensure that the $\mathrm{BHJ}$ absorbs as many of the incoming photons as possible and generates as many moving charges as possible. The big scientific question of the optimal morphology remains.

This is still an open question, and the procedure for optimizing the morphology for a specific combination of donor and acceptor is so far done by trial and error. Optimal coating conditions for the blend P3HT:O-IDTBR and P3HT:EHIDTBR have been reported ${ }^{13,14}$. Similar experimental parameters were used here to prepare both P3HT:O-IDTBR and P3HT:EH-IDTBR roll-coated on a flexible substrate at $60{ }^{\circ} \mathrm{C}$, as described by Kuan Liu et al. ${ }^{15}$. The roll-coated OPVs have an inverted structure ${ }^{16}$ and were fabricated on flexible substrates without indium tin oxide (ITO-free), with the structure PET/Ag-grid/PEDOT:PSS/ZnO/P3HT:O-IDTBR or EH-IDTBR/PEDOT:PSS/Ag-grid, where the light enters through the PET substrate. PEDOT:PSS is an abbreviation for poly(3,4-ethylenedioxythiophene) polystyrene sulfonate 
and PET is poly(ethylene terephthalate). After fabrication, the final stack is cut to small solar cells with a photoactive area of $1 \mathrm{~cm}^{2}$.

Standard means to characterize the performance of solar cells include measuring the current density vs. voltage $(J-V)$ curves and the external quantum efficiency (EQE) spectra. For both P3HT:O-IDTBR and P3HT:EH-IDTBR, the results are shown in Figure 3 and Table 1. The low 2.2\% PCE of the P3HT:EH-IDTBR solar cell is due to its lower short circuit current (JSC), which is partially limited by the series resistance (Rs) of $9.0 \Omega \cdot \mathrm{cm}^{2}$ compared to that of P3HT:O-IDTBR of $7.7 \Omega \cdot \mathrm{cm}^{2}$. The open-circuit voltage (VOC), is similar in both devices (Table 1), which reflects the electronic similarity of the two acceptors. The photovoltaic band-gap of the P3HT:O-IDTBR and P3HT:EH-IDTBR solar cells are $1.60 \mathrm{eV}$ and $1.72 \mathrm{eV}$, respectively, in agreement with the optical properties observed by the redshift in the EQE shown in Figure 3 and reported by Enrique P. S. J. et al. ${ }^{13}$. Usually, a redshift is due to a more crystalline structure, thus it is expected that O-IDTBR possesses a higher degree of crystallinity than EH-IDTBR for the specific coating conditions. The improved JSC of the P3HT:O-IDTBR solar cell is in part due to its broader spectral absorbance and the device processing improvements. The integrated EQE currents for the EH-IDTBR and O-IDTBR based devices are 5.5 and $8.0 \mathrm{~mA} / \mathrm{cm}^{2}$ under 1 sun illumination as shown in Figure 3. From the EQE profiles, it can be seen that the $1: 1$ mass ratio is close to ideal for P3HT:O-IDTBR but is not optimal for P3HT:EH-IDTBR. The differences in device performance can partially be explained by the presence of pinholes in the P3HT:EH-IDTBR film, whereas P3HT:O-IDTBR appears smooth as shown in Figure 4. The pinholes in the P3HT:EH-IDTBR material system are covered by the subsequent PEDOT:PSS layer during the solar cell fabrication, preventing short-circuiting of the devices. Furthermore, the side chains of the acceptors are respectively linear and branched, which causes their solubility to differ, and thus their drying kinetics. One can use a mini roll-to-roll coater to probe the drying kinetics while coating, which mimics the same coating conditions of the solar cell fabrication ${ }^{17}$, as first demonstrated in $2015^{18}$.

Here, we present the application of an improved mini rollto-roll slot-die coating machine to perform in situ GISAXS experiments, to probe the morphology of the drying inks for OPVs with an in-house X-ray source. GISAXS is the preferred method to probe the size, shape, and orientation distributions in or on thin-films ${ }^{19}$. When performing a GISAXS experiment, the scattered $\mathrm{X}$-rays that probe the sample are collected on a 2D detector. The challenging part is to choose the right model to retrieve the desired information from the sample that is being studied. Therefore, prior information regarding the sample structure is essential to choose a suitable model. Such knowledge can be obtained from atomic force microscopy (AFM), transmission electron microscopy (TEM), or molecular dynamics simulations ${ }^{7}$. Here, we will present why and how to apply the framework of Teubner and Strey $^{20}$ to model the data obtained from the in situ GISAXS experiments to retrieve the size distributions of the domains inside the ink for BHJs while drying. There are two benefits of using a mini roll-to-roll coater. First, it mimics the large-scale production 1:1; thus, we are certain the device performance and active layer can be compared directly. Second, by using this method, we are capable of having enough fresh ink in the beam to allow an in situ experiment with a laboratory X-ray source. The methods to perform and analyze the morphology of thin-films with GISAXS have been rapidly developing over the past decade $18,21,22,23,24,25,26,27,28$. Usually, when performing an in situ GISAXS experiment 
to probe drying kinetics of the active layer in OPVs, a synchrotron source is needed ${ }^{18,26,27}$. Synchrotron radiation is in general preferred over an in-house X-ray source to perform such an experiment to provide better time resolution and better statistics. However, synchrotrons are not available on a day-to-day basis and cannot be adjusted to fit a production line, therefore an in-house X-ray source can serve as a useful everyday tool for optimizing ink-formulations, coating conditions, and to gain fundamental insight in the physics of drying kinetics. The most significant disadvantage for using an in-house X-ray source is material consumption. As the flux of X-rays is at least five orders of magnitude smaller than at a synchrotron, more material is needed to obtain sufficient statistics. Therefore, this technique is not yet suitable for new material discovery, where only small amounts of materials are accessible. For materials that are cheap and easy to synthesize, which is also a dominant factor for scalability ${ }^{29}$, this method will be advantageous over the usage of synchrotrons in the pursuit of closing the efficiency gap for large scale roll-to-roll coated OPVs ${ }^{10,30}$.

This article will guide the reader through performing in situ GISAXS experiments to probe drying kinetics of inks applicable for large-scale production of OPVs. An example of data reduction and analysis is presented along with a discussion of various models to interpret the data.

\section{Protocol}

This protocol is divided into five subsections. First, a procedure for preparation of inks is presented. Second, the procedure for preparing and performing roll-to-roll slotdie coating is described. Third, a step-by-step guide for performing an in situ GISAXS experiment is presented.
Fourth, a procedure for data correction and analysis is outlined. Finally, the results are reported and discussed.

\section{Preparation of inks for roll-to-roll coating (Day 1)}

1. Read the MSDS of the polymers, molecules, and solvents carefully before starting an experiment.

2. Place $90 \mathrm{mg}$ of $\mathbf{O}-\mathbf{I D T B R}$ and $90 \mathrm{mg}$ of $\mathbf{P} \mathbf{3 H T}$ in a $10 \mathrm{~mL}$ vial.

3. Dissolve the P3HT:O-IDTBR solids in $4.5 \mathrm{~mL}$ of dichlorobenzene:bromoanisole (0.95:0.05) solvent mixture. The final concentration of the ink is then $180 \mathrm{mg} /$ $4.5 \mathrm{~mL}=40 \mathrm{mg} / \mathrm{mL}$

4. Place a magnetic stirrer in the solution and seal the vial immediately. Place the sealed vial on a hot plate with a magnetic rotator. Set the rotation at $300 \mathrm{rpm}$ and the hot plate at $60^{\circ} \mathrm{C}$, and leave it stirring for 12 hours.

5. Repeat the procedure for ink preparation for P3HT:EHIDTBR.

\section{Preparing and performing roll-to-roll slot die coating (Day 2)}

1. Turn off the rotation and the hot plate. Remove the vials from the hot plate at least 1 hour before using it, to achieve room-temperature of the inks when coating.

2. Wind $18 \mathrm{~m}$ of PET substrate foil on the feeder roll. Attach the free end of the substrate to the winder roll as shown in Figure 5. Start the motor to run the foil $0.2 \mathrm{~m}$ to tighten the substrate.

3. Set the first hot plate of the roll-to-roll setup at the desired temperature (i.e., $60^{\circ} \mathrm{C}$ ). Set the second hot plate at $80^{\circ} \mathrm{C}$ to ensure that the film is dried when wound 
onto the winder roll. Wait approximately $15 \mathrm{~min}$ for the temperature of the two hot plates to stabilize.

4. Load $2.2 \mathrm{~mL}$ of ink into a $3 \mathrm{~mL}$ syringe. Mount the syringe in the pump. Attach a tube from the syringe to the slotdie coating head.

5. Place the coating head close to the end of the first hot plate by adjusting the horizontal translation stage, and place the meniscus guide approximately $5 \mathrm{~mm}$ above the substrate.

6. Set the syringe pump at the following coating settings: Rate: $0.08 \mathrm{~mL} / \mathrm{min}$, the diameter of syringe: $12.7 \mathrm{~mm}$.

7. Control the thickness of the active layer $d$ by adjusting the flow rate, $f$, and the speed of the moving substrate, $v$, according to this formula:

$d=\frac{c f}{\rho v w}$

where $w$ is the width of the film (determined by the meniscus guide), and $\rho$ is the density of the materials in the ink. In this experiment, we use $v=0.6 \mathrm{~m} / \mathrm{min}$ with a flow rate of $f=0.08 \mathrm{~mL} / \mathrm{min}$, resulting in a film with a dry thickness of $425 \mathrm{~nm}$.

8. Critical step: Manually press the ink from the syringe through the hose and stop $1 \mathrm{~cm}$ before the ink reaches the coating head. Start the syringe pump and wait for a droplet to wet the entire width of the meniscus-guide. Immediately, lower the coating head to wet the substrate with the ink and then raise the meniscus guide to the coating position $2 \mathrm{~mm}$ above the substrate.

9. Start the motor that winds up the substrate and start coating the ink.

10. To stop coating, stop the pump and stop the moving substrate. Raise the coating head to a safe height (approx. $20 \mathrm{~mm}$ above the substrate). Then clean the head and hose with tetrahydrofuran.

\section{Day 2: In situ roll-to-roll GISAXS experiments}

1. X-ray setup description

NOTE: The total length of the Grazing Incidence Small Angle X-ray setup is $4.5 \mathrm{~m}$ and consists of an X-ray source, focusing optics, a collimation section, a sample stage, a flight tube, beam stop, and a detector, as shown in Figure 6. The X-ray source is a rotating anode from Rigaku.

1. Use a copper anode for this experiment and set the operating condition to $36 \mathrm{kV}$ and $36 \mathrm{~mA}$.

2. Operate the experiment in fine-focus-mode. The optics consist of a 2D focusing multilayer monochromator, which is aligned to optimize the reflection of the Copper $K_{\alpha}$ radiation with $a$ wavelength of $1.5418 \AA$. The collimation section consists of three pinholes placed $45 \mathrm{~cm}, 141 \mathrm{~cm}$, and $207 \mathrm{~cm}$ downstream from the X-ray source, respectively. The diameters of the pinholes are 0.75 $\mathrm{mm}, 0.3 \mathrm{~mm}$, and $1.0 \mathrm{~mm}$ in diameter, respectively, with a probe size of approximately $1.0 \mathrm{~mm}$ at the sample position, corresponding to a beam footprint of $286 \mathrm{~mm}$ at $0.2^{\circ}$ incidence angle. The beam has a flux at the sample of $5 \times 10^{6}$ photons s$~^{-1}$ and a profile as shown in Figure 7, left panel.

3. Ensure that there are at least three controllable motors at the sample stage to adjust the position of the mini roll-to-roll coater. Downstream of the sample stage, install a $166 \mathrm{~cm}$ evacuated flight tube (less than 0.01 mbar) on the rack followed by an Eiger $4 \mathrm{M}$ X-ray detector ${ }^{31}$. 
2. Install the roll coater.

1. Fasten the mini roll-to-roll coater to the goniometer. Mount the goniometer with the roll-to-roll coater on the optical bench at the sample position.

2. Fasten the three motor cables. Fasten the goniometer stage to the bench. Approach the flight tube as close to the mini roll-to-roll coater as possible.

3. Critical step: Align the sample position. Coat $10 \mathrm{~cm}$ of the ink and roll the film into the beam. The procedure for alignment is threefold.

1. Align the sample parallel to the beam. This is achieved by an iterative process of scanning the summed intensity of the direct beam as a function of the vertical sample position and incidence angle.

2. Align the sample to a specific incidence angle, $\alpha_{i}$, by calculating the angle from the reflected beam on the detector with the following formula:

$\alpha_{i}=\frac{1}{2} \arctan \left(\frac{R B[\mathrm{~cm}]-D B[\mathrm{~cm}]}{S D D[\mathrm{~cm}]}\right)$

where $R B$ is the reflected beam position, $D B$ is the direct beam position (both measured in $\mathrm{cm}$ ), and SDD is the sample-to-detector distance, here 166 $\mathrm{cm}$.

3. Optimize the intensity in the reflected beam by scanning the height of the sample position. For this experiment, use an incidence angle of $0.2^{\circ}$. The $2 \mathrm{D}$ data for this procedure is shown in Figure 7.

4. Choice of incidence angle

1. Choose the angle of incidence to ensure penetration in the layers of interest. Here this will be an incidence angle of $0.2^{\circ}$.
NOTE: For this experiment, the film of interest consists of solvent, P3HT and IDTBR. Both P3HT and O-IDTBR have a higher density than the solvent, and presumably has the highest critical angle for total reflection. The critical angle of $\mathrm{P} 3 \mathrm{HT}$ and $\mathrm{O}-$ IDBTR can vary according to their packing resulting in a critical angle varying from $0.16^{\circ}-0.19^{\circ}$, assuming a density of the solid of $1.1-1.35 \mathrm{~g} / \mathrm{cm}^{3}$. Thus, $0.2^{\circ}$ was chosen to ensure penetration into the bulk of the film. To perform a GISAXS experiment on another sample system, evaluate the best-suited incidence angle for a specific sample 28,59 .

5. Install the beam-stop just before the detector, which will extend the lifetime of the detector. Use a circular beam stop for the direct beam and an additional thin rectangular beam stop to block the reflected beam. The beam stop needs to block the direct beam but at the same time allow detection of scattering at low scattering angles.

NOTE: It is possible to perform this experiment without a beam-stop to allow constant tracking of the reflected beam.

6. Install the point-suction. Place the point-suction to remove all the gases from the evaporating solvents. Fasten the point-suction to ensure the airflow at the sample is the same at each experiment.

7. Load a syringe with $2.2 \mathrm{~mL}$ of ink and place the syringe in the syringe pump. Manually press the ink from the syringe through the hose and stop $1 \mathrm{~cm}$ before the ink reaches the coating head.

8. Set the distance from the coating head to the X-ray beam. Place the coating head at a position of $120 \mathrm{~mm}$ displaced from the X-ray beam along the moving direction of the foil, to ensure a drying time of 12 seconds (for 3 seconds 
of drying time, place the coating head $30 \mathrm{~mm}$ from the $\mathrm{X}$ ray beam) as shown in Figure 8 .

9. Start roll-to-roll slot-die coating. Place the height of the meniscus-guide $5 \mathrm{~mm}$ above the substrate.

1. Start the syringe pump and wait for a droplet to wet the entire width of the meniscus-guide. Immediately, lower the coating head to wet the substrate with ink, and then raise the meniscus guide to the coating position $2 \mathrm{~mm}$ above the substrate.

2. Start the motor that winds up the substrate and start coating the ink.

10. Start recording data. Open the X-ray shutter and start recording data for 3000 seconds.

NOTE: This experiment was done with an exposure of 3000 seconds, a more robust method is to perform several shorter exposures to allow flexible temporal binning of data.

11. Monitor the quality of the coated film with a camera. Look for de-wetting effects of the film on the substrate and meniscus misalignments. If necessary, stop the measurements and redo the experiment.

1. At the end of experiment, close the X-ray shutter. Turn off the X-ray beam remotely. Stop the syringe pump, raise the coating head and unwind the foil. For a series of experiments, repeat this procedure with a different setting.

\section{Data treatment}

NOTE: Four experiments were performed and the specific parameters can be found in Table 2 . One of the experiments with P3HT:O-IDTBR was stopped after 2732 seconds due to a syringe pump error; therefore, the signal must be normalized to account for the difference in acquisition time.
1. Data correction

1. First, use a mask to correct for the beam stop and dead pixels ${ }^{33}$. Follow with a cosmic ray filter develop by SAXSLAB, then flat field correction, time correction, a filter for the additional scattering peaks arising from polycrystalline aluminum that are clearly visible in the two datasets shown in Figure 9, left panel.

2. From real to reciprocal space

1. Convert the $2 \mathrm{D}$ data from real space to the reciprocal space vector $\mathbf{q}_{x, y, z}$ in units of $\AA^{-1}$ by using this formula:

$q_{x, y, z}=\frac{2 \pi}{\lambda}\left[\begin{array}{c}\cos \left(\alpha_{f}\right) \cos \left(2 \theta_{f}\right)-\cos \left(\alpha_{i}\right) \\ \cos \left(\alpha_{f}\right) \sin \left(2 \theta_{f}\right) \\ \sin \left(\alpha_{f}\right)+\sin \left(\alpha_{i}\right)\end{array}\right]$

Here, $\alpha_{i}$ is the incidence angle with respect to the normal of the surface, $\alpha_{f}$ is the exit/final angle on the detector (vertical on the detector), $2 \theta_{f}$ is the exit/final angle in the plane (horizontal on the detector), and $\lambda$ is the wavelength of the incident beam. Assume the wavelength to be preserved, also known as elastic scattering ${ }^{34}$.

3. Horizontal line integration at the Yoneda line

1. Determine the $x$ and $y$ coordinate for the center of the beam, respectively, the sample to detector distance $(S D D=1.66 \mathrm{~m})$, the wavelength of the $X$ rays $(1.5418 \AA$ ), and pixel size in each direction (75 $\left.x 75 \mu \mathrm{m}^{2}\right)$.

2. Calculate the expected position of the Yoneda line from the critical angle of the investigated sample $28,34,35,36$. 
3. Retrieve the scattering intensity as a function of scattering vector $\mathbf{q}_{\mathbf{x y}}$, by using a MatLab script or by using dedicated software such as DPDAK or Xi$\mathrm{Cam}^{38,39}$. Perform horizontal line integration along the Yoneda line as indicated in Figure 9, with a width of 50 pixels to each side to ensure a satisfying signalto-noise ratio.

4. Binning of horizontal integration

1. To avoid oversampling (see Figure 9, right panel) and to increase the signal-to-noise ratio for the large scattering vectors $\mathbf{q}_{\mathbf{x y}}$, bin the data logarithmically 40 .

2. Do not bin the data points up until $\mathbf{q}_{\mathbf{x y}}=0.5 \times 10^{-3} \AA$. This is not necessary due to the high intensity and mutual distance in q-space, which ensures that there are no redundant data points.

3. From $\mathbf{q}_{\mathbf{x y}}=0.5 \times 10^{-3} \AA$ and above, divide the $\mathbf{q}_{\mathbf{x y}} \mathbf{y}^{-}$ axis into 135 equally spaced bins on a logarithmic scale, in such a manner that the first bin at $\mathbf{q}_{\mathbf{x y}}=0.53$ $x 10^{-3} \AA$ is the mean of two data points, and the final binned point at $q_{x y}=0.3 \AA$ is a mean of 24 points.

5. Applying the Teubner-Strey model

1. Apply three Teubner-Strey contributions to describe the data. The first two contributions describe the contrast between the donor/acceptor and the last contribution describes the contrast between larger aggregates of materials surrounded by the solvent. The mathematical expression of the scattering intensity is as follows:

$\mathbf{I}\left(q_{x y}\right) \propto \sum_{\mathrm{i}=1}^{3} \frac{1}{\mathrm{a}_{1, \mathrm{i}}+\mathbf{c}_{1, \mathrm{i}} q_{x y}{ }^{2}+\mathrm{c}_{2, \mathrm{i}} q_{x y}{ }^{4}}+\beta$ where $\beta$ is a constant background, the parameters $a_{1, i}, c_{1, i}, c_{2}, i$ are defined in terms of the domain size, $d_{i}$, and correlation length $\xi_{i}$, as follows:

$$
\begin{aligned}
& \mathrm{a}_{1, \mathrm{i}}= \\
& {\left[1+\left(\frac{2 \pi \mathrm{d}_{\mathrm{i}}}{\xi_{\mathrm{i}}}\right)^{2}\right]^{2}, \mathbf{c}_{1, \mathrm{i}}=-2 \xi_{\mathrm{i}}^{2}\left(\frac{2 \pi \mathrm{d}_{\mathrm{i}}}{\xi_{\mathrm{i}}}\right)^{2}+2 \xi_{\mathrm{i}}^{2}, \mathbf{c}_{2, \mathrm{i}}=\xi_{\mathrm{i}}^{4}}
\end{aligned}
$$

From equations (4), the domain size and correlation length can be expressed as follows:

$d_{i}=2 \pi\left[\frac{1}{2}\left(\frac{a_{1, i}}{c_{2, i}}\right)^{1 / 2}-\frac{1}{4} \frac{c_{1, i}}{c_{2, i}}\right]^{-1 / 2}$

and

$\xi_{i}=\left[\frac{1}{2}\left(\frac{a_{1, i}}{c_{2, i}}\right)^{1 / 2}+\frac{1}{4} \frac{c_{1, i}}{c_{2, i}}\right]^{-1 / 2}$

where $d_{1}, \xi_{1}, d_{2}$ and $\xi_{2}$ are the parameters for the donor/acceptor phases, and $d_{3}$ and $\xi_{3}$ are the parameters for the aggregate/solvent phases. The fitted models are shown in Figure 10. The results from the four fits, based on the described TeubnerStrey model, are found in Table 3.

\section{Representative Results}

First and foremost, this paper describes the method and protocol for performing a successful roll-to-roll in situ in-house GISAXS experiment to probe drying thin-films. Based on the fitting, it can be deduced that the Teubner-Strey model successfully describes the data for P3HT:EH-IDTBR and P3HT:O-IDTBR for both 12 and 3 seconds of drying as shown in Figure 10.

The characteristic length scales based on the Teubner-Strey model can be found in Table 3 with the corresponding uncertainties in Table 4. For all four fits, the domain size and 
correlation length for the highest $\mathbf{q}_{\mathbf{x y}}, d_{1}$ and $\xi_{1}$, are close to the same value, varying from $12.0 \pm 1.7 \mathrm{~nm}$ to $12.5 \pm 2.2 \mathrm{~nm}$ and from $3.9 \pm 0.4 \mathrm{~nm}$ to $5.0 \pm 0.4 \mathrm{~nm}$. These two characteristic sizes and lengths are similar to the values reported in literature for the dry film bulk heterojunctions of P3HT:IDTBR and $\mathrm{P} 3 \mathrm{HT}: \mathrm{PCBM}^{41,42}$. For the large structures, $d_{3}$ and $\xi_{3}$, there is a clear tendency for the structures to become larger as it dries. For P3HT:EH-IDTBR it increases from 225 $\pm 10.3 \mathrm{~nm}$ to $562 \pm 11.1 \mathrm{~nm}$, and for P3HT:O-IDTBR it increases from $241 \pm 4.1 \mathrm{~nm}$ to $489 \pm 9.2 \mathrm{~nm}$. The correlation lengths, $d_{2}$, are found to $30 \pm 12 \mathrm{~nm}$ and $34 \pm 3.5 \mathrm{~nm}$ for P3HT:O-IDTBR and $41 \pm 14 \mathrm{~nm}$ for both P3HT:EHIDTBR experiments. Noticeably, $d_{2}$ is more pronounced after 3 seconds of drying than after 12 seconds of drying for P3HT:O.IDTBR as opposed to P3HT:EH-IDTBR, where the $d_{2}$ is more pronounced after 12 seconds of drying than after 3 seconds of drying. Whether $d_{2}$ dissolves to contribute to the signal obtained at $d_{1}$ or cluster to contribute to $d_{3}$ is not determined in this experiment.

Based on the formalism by Teubner-Strey ${ }^{20}$, the characteristic parameters for $a_{1, i}, c_{1, i}, c_{2, i}$ indicate that small length scales, $a_{1,1}, c_{1,1}, c_{2,1}, a_{1,2}, c_{1,2}, c_{2,2}$, are characteristic for an early stage of spinodal decomposition where the two phases are intermixing ${ }^{43}$. This is in agreement with the general understanding of the morphology of donor/ acceptor intermixing. The large length scales, a1,3, $c 1,3$, $c_{2,3}$, are characteristic of micro emulsions ${ }^{20}$, which is caused by the contrast (electron density difference) between aggregates of material and solvent. From this experiment, it is impossible to distinguish whether these characteristic parameters of $d_{3}$ are caused by the electron density difference between either P3HT:O-IDTBR/Solvent, O-IDTBR/ Solvent, or P3HT/Solvent.
To fit a model to X-ray, scattering data is an inherent inverse problem. Therefore, several models can be applied to describe the scattering data. For this analysis, the formulation by Teubner and Strey ${ }^{20,44}$ was applied to fit the data. The framework originates from an order parameter expansion of the Landau free energy to describe the scattering intensity from two-phase systems. Interpretation of the model is an abstract geometrical structure of a two-phase system with a characteristic domain size and a correlation length as known from statistical mechanics ${ }^{45}$.

There exist many sophisticated models that can predict the 2D data from GISAXS experiments, and user-friendly software programs ${ }^{34,46}$ to model this. Usually, GISAXS data from BHJ are modelled with the Distorted Wave Born Approximation (DWBA) with very high accuracy $27,40,47,48$. Nevertheless, the main disadvantage is that the modelled structure is not corresponding to the complexity expected in a BHJ. A simpler approach is to restrict the analysis to the qxy direction. When only 1D horizontal line cuts in $\mathbf{q}_{\mathbf{x y}}$ are considered, it is fair to assume that the main contributor to scattering arises from the lateral structures present in the film. Assuming this it can be shown that the momentum transfer retrieved from the horizontal line cuts corresponds to transmission $\mathrm{SAXS}^{49,50}$, from where Teubner-Strey is derived ${ }^{20}$ and therefore valid for the analysis presented here.

This model is chosen for three reasons: First, the model is an analytical expression that has been proved to fit a variety of two-phase systems including $\mathrm{BHJ}^{20,26,51}$, and it can be employed for very fast fitting algorithms, which is applicable for large-scale quality control and for in situ measurements. Second, to the best of our knowledge, this model is in agreement with the morphology observed for P3HT:O-IDTBR by transmission electron microscopy (TEM) ${ }^{52}$ and atomic 
force microscopy (AFM $)^{42}$. Third, it is a simple model i.e. it spans a small parameter space.

Furthermore, this paper documents that probing drying kinetics of non-fullerene organic solar cells with an in-house
X-ray source is possible. In addition, this method has the potential to serve as a tool for accelerating the research in large-scale roll-to-roll coated OPVs.

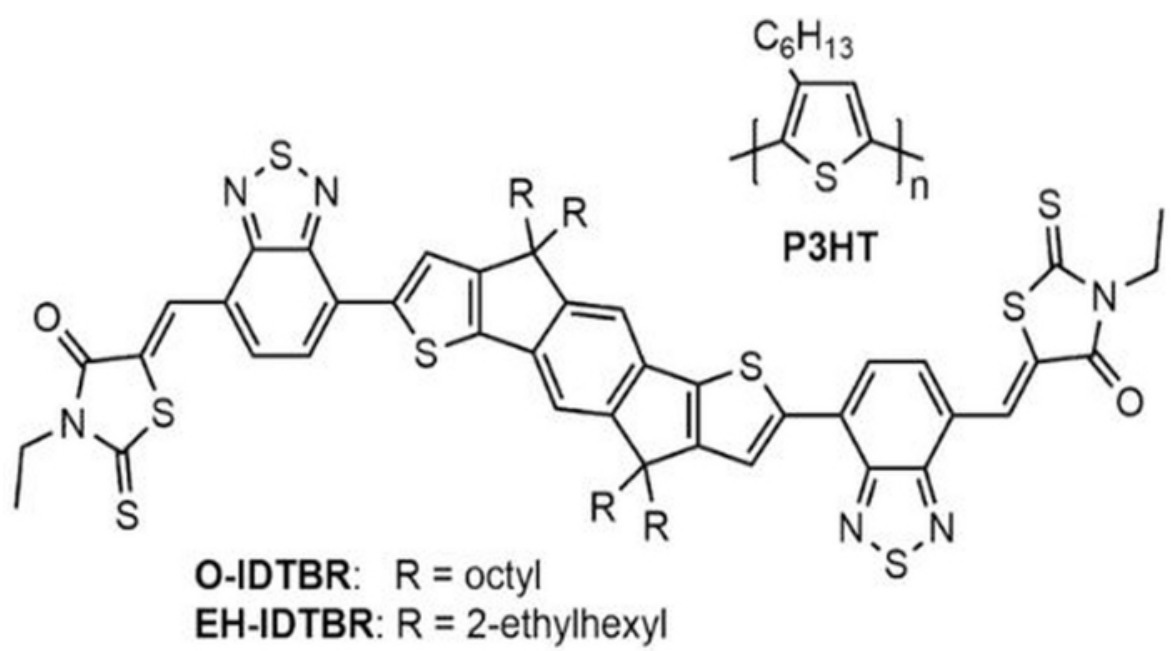

Figure 1: Chemical structure of P3HT, O-IDTBR, and EH-IDTBR. Please click here to view a larger version of this figure.
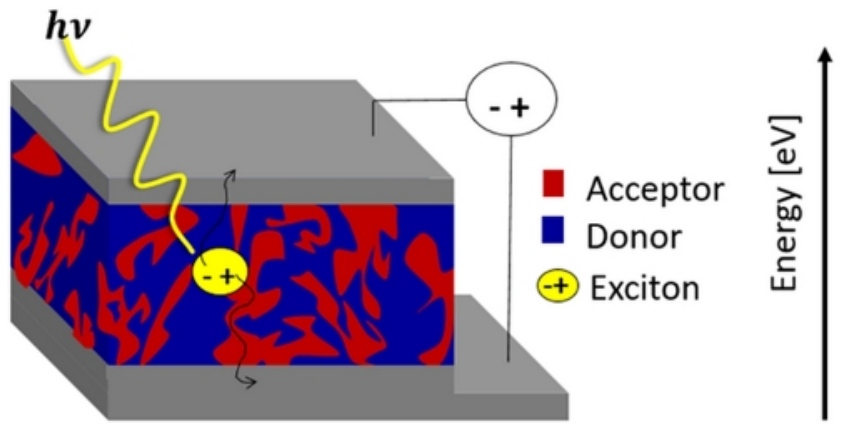

LUMO

\section{LUMO}

HOMO HOMO

Figure 2: (Left) Working principle of a bulk heterojunction organic solar cell. Sunlight is creating an exciton, which upon separation allows the hole and the electron to diffuse to the cathode and anode, respectively. (Right) Energy diagram of the HOMO and LUMO levels of the donor and acceptor. Please click here to view a larger version of this figure. 


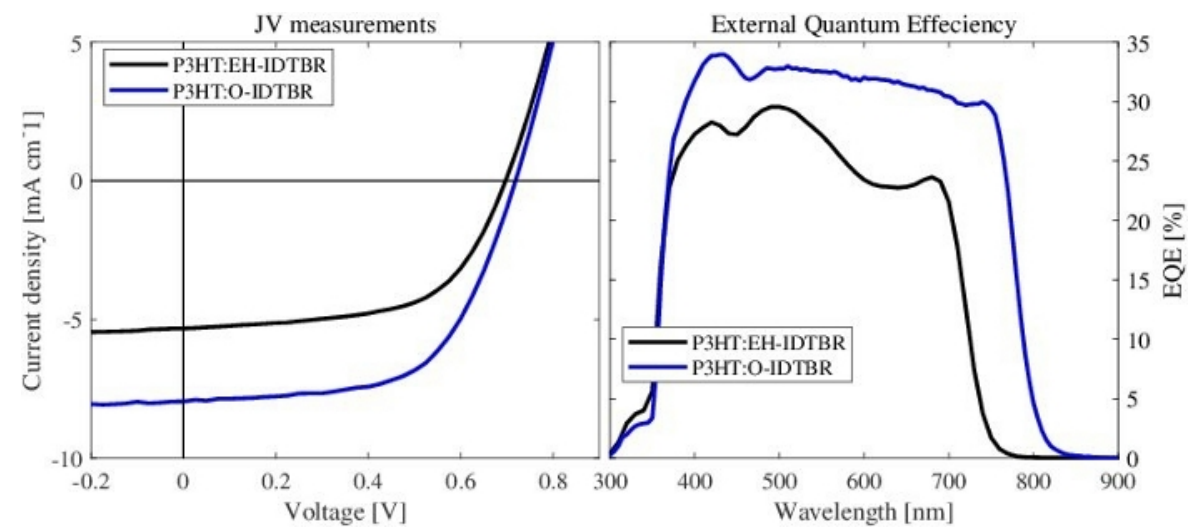

Figure 3: (Left) JV-curves for roll slot die coated on flexible substrate P3HT:O-IDTBR and P3HT:EH-IDTBR, corresponding to the best performing devices shown in Table 1. (Right) EQE curves of roll slot die coated on flexible substrate P3HT:OIDTBR and P3HT:EH-IDTBR. Please click here to view a larger version of this figure.

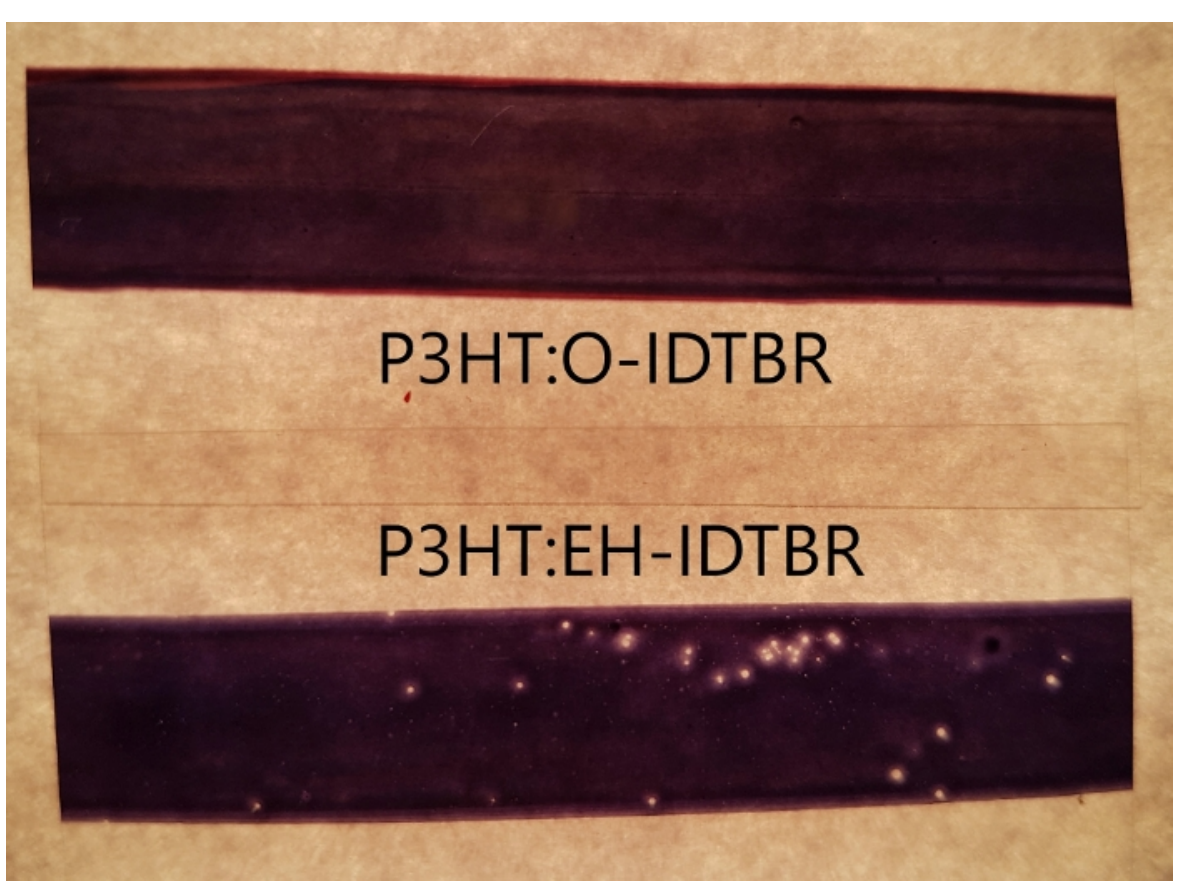

Figure 4: Images of the two inks, roll coated on PET substrate. Top is P3HT:EH-IDTBR and bottom is P3HT:O-IDTBR.

Please click here to view a larger version of this figure. 


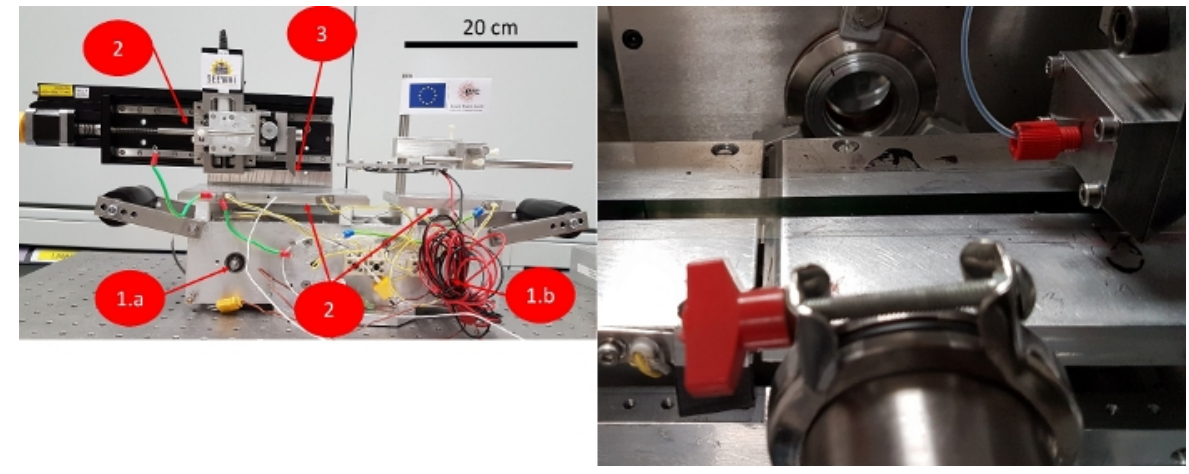

Figure 5: (Left) Image of mini roll-to-roll coater. 1. a) 1.b) are indicating the rotation centre of the foil feeder and receiver, respectively. The motor is on the back side of the roll-to-roll coater and is a stepper motor. 2) The translation stages for the coating head, which can move in all three directions, along the foil, up and down, and outwards and inwards. 3) The slot die coating head, where a hose with ink can be fastened. 4) The two hot plates, indicated by the two arrows, which will heat the moving substrate to the desired temperature. In this experiment, it was set to $60^{\circ} \mathrm{C}$. All parts are controlled remotely. (Right) Roll-to-roll coater installed at the GISAXS set-up. Please click here to view a larger version of this figure.

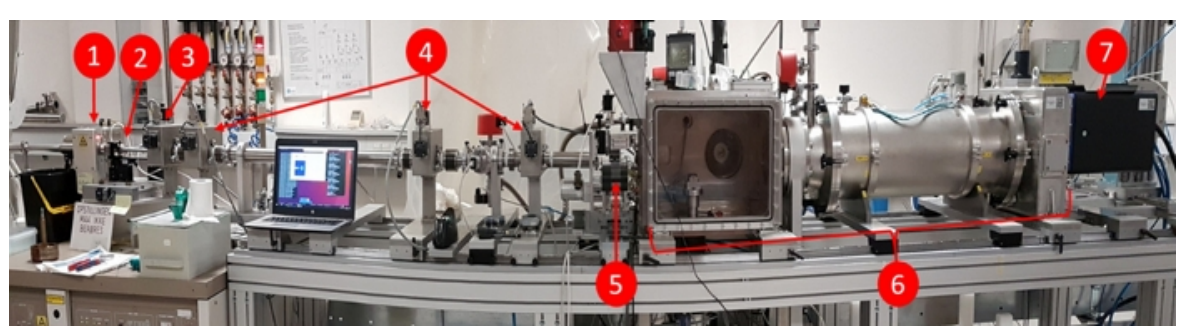

Figure 6: Experimental set-up for Grazing Incidence Small Angle X-ray Scattering. 1) X-ray source is a rotating anode made by Rigaku. A rotating anode made from copper was operated at $36 \mathrm{kV} 36 \mathrm{~mA}$. 2) Optics section, where the $\mathrm{Cu} \mathrm{K}_{\alpha}$ characteristic fluorescence from the rotating anode diffract from a single bounce multilayer mirror, which makes the beam monochromatic at wavelength: $\lambda=1.5418 \AA$. 3) Attenuator station, which was not applied for this experiment. 4) Collimation section, consisting of three pinholes after each other as indicated with the three arrows. The diameter of the pin holes are $0.75 \mathrm{~mm}, 0.3 \mathrm{~mm}$, and $1.0 \mathrm{~mm}$, respectively. 5) Mini roll-to-roll coater position attached to a vertical moving axis and a goniometer to control the incidence angle. 6) Flight tube in vacuum. 7) Eiger $4 \mathrm{M}$ detector. Please click here to view a larger version of this figure. 

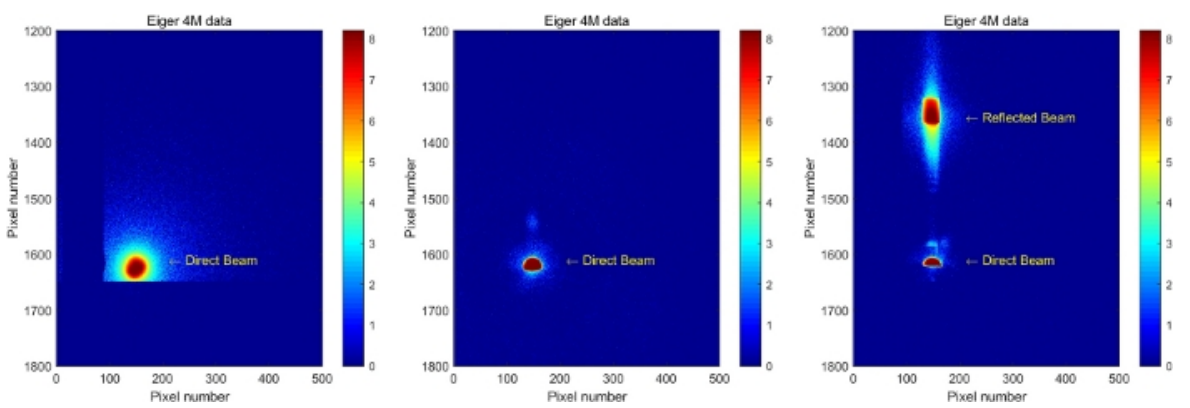

Figure 7: Three steps in the alignment procedure illustrated as raw Eiger 4M data. (Left) First, make sure there is nothing blocking the direct beam. In this example the beam stop is located just to the left and beneath the direct beam. (Middle) Scan the sample along the vertical axis and place it where half of the direct beam is blocked by the sample. Then rotate the sample to gradually changing the incidence angle and place the sample where the intensity of the direct beam is highest. This procedure must be done 3-5 times to ensure that the sample is completely parallel with the beam. (Right) Rotate the sample until a clear reflection occur on the detector. From these two positions, the exact incident angle can be calculated (see text). Please click here to view a larger version of this figure.
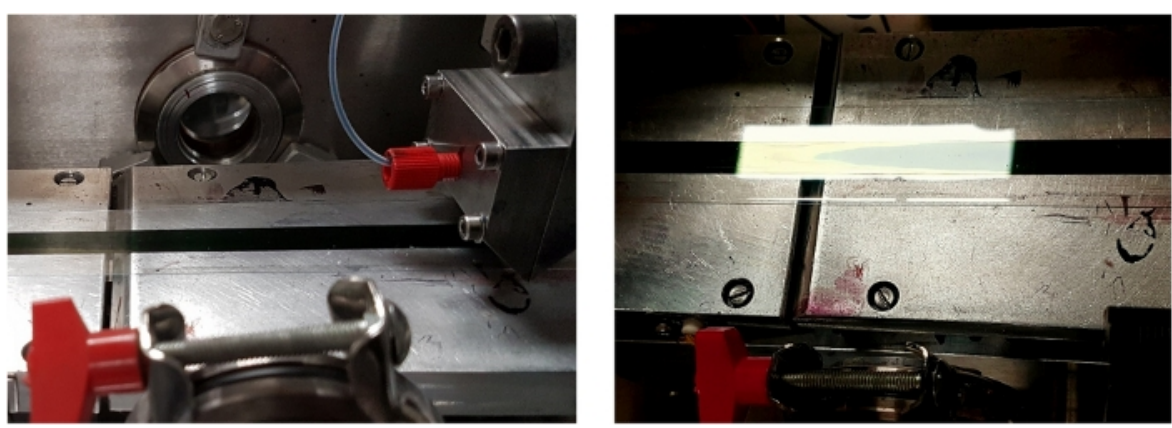

Figure 8: Two stages of drying seen from two different angles. (Left) is the wet stage, where the film has been drying for 3 seconds before being probed. (Right) is the dry stage where the film has been drying for 12 seconds. The contrast have been increased to visualize the effect of the edges drying. Please click here to view a larger version of this figure. 

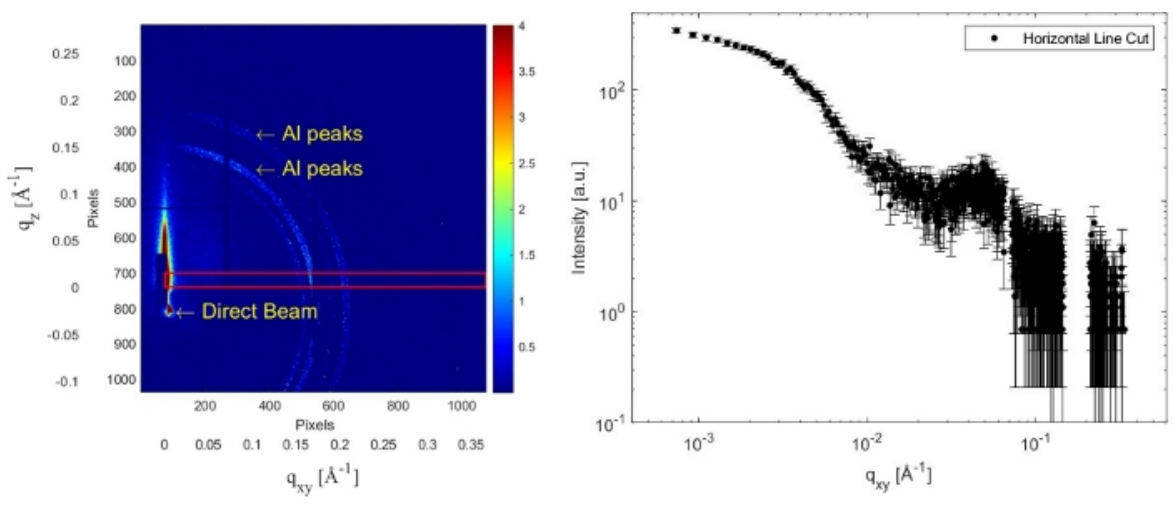

Figure 9: (Left) 2D data P3HT:O-IDTBR at 12 seconds of drying with 3000 seconds of acquisition time. The red rectangle indicates where the horizontal integration has been performed and the intense areas marked as aluminum peaks originates from the heater plate. (Right) The horizontal integration from the red rectangle where the q-vectors of the aluminum peaks are omitted from the integration. Please click here to view a larger version of this figure.

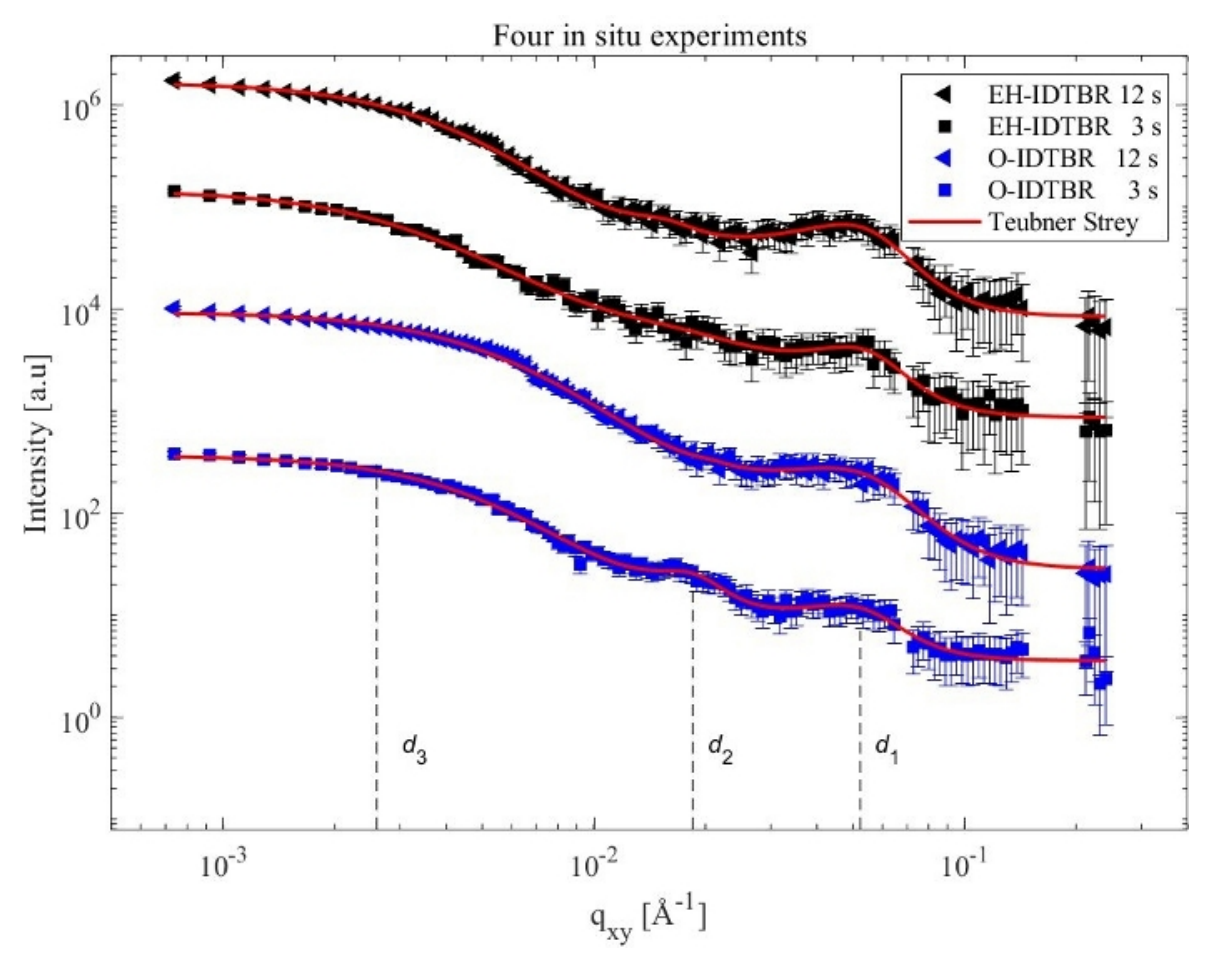

Figure 10: Binned horizontal line integration for the four experiments: P3HT:EH-IDTBR (black) and P3HT:O-IDTBR (blue) probed at both 12 seconds (triangles) and 3 seconds (squares) of drying along with the Teubner-Strey fits. Please click here to view a larger version of this figure. 


\begin{tabular}{|l|c|c|} 
& Drying time (s) & Measuring time (s) \\
\hline P3HT:O-IDTBR & 3.0 & 2732 \\
\hline P3HT:O-IDTBR & 12 & 3000 \\
\hline P3HT:EH-IDTBR & 3.0 & 3000 \\
\hline P3HT:EH-IDTBR & 12 & 3000 \\
\hline
\end{tabular}

Table 1: Optoelectronic characteristics of $1 \mathrm{~cm}^{2}$ organic solar cells based on P3HT:O-IDTBR and P3HT:EH-IDTBR showing the power conversion efficiency (PCE), the short circuit current density (JSC), the fill factor (FF), and the open circuit voltage (VOC), under $100 \mathrm{~mW} / \mathrm{cm}^{2}$ illumination.

\begin{tabular}{|c|c|c|c|c|}
\hline P3HT:EH-IDTBR & PCE & & $\mathrm{FF}$ & VOC \\
\hline 1 & 2.20 & 5.32 & 59.43 & 0.70 \\
\hline 2 & 1.81 & 4.53 & 56.97 & 0.70 \\
\hline 3 & 1.97 & 4.83 & 57.55 & 0.71 \\
\hline 4 & 2.17 & 5.10 & 60.00 & 0.71 \\
\hline 5 & 2.18 & 5.28 & 58.49 & 0.71 \\
\hline average & 2.07 & 5.01 & 58.49 & 0.70 \\
\hline stand dev sample & 0.15 & 0.30 & 1.13 & 0.00 \\
\hline \multicolumn{5}{|l|}{ P3HT:O-IDTBR } \\
\hline 1 & 3.38 & 7.95 & 60.48 & 0.72 \\
\hline 2 & 3.33 & 7.75 & 60.36 & 0.71 \\
\hline 3 & 2.97 & 7.19 & 58.72 & 0.70 \\
\hline 4 & 3.20 & 7.48 & 60.15 & 0.71 \\
\hline 5 & 3.24 & 7.54 & 60.68 & 0.71 \\
\hline average & 3.22 & 7.58 & 60.08 & 0.71 \\
\hline stand dev sample & 0.14 & 0.26 & 0.70 & 0.00 \\
\hline
\end{tabular}

Table 2: Overview of data. P3HT:O-IDTBR with a drying time of $3.0 \mathrm{~s}$ was stopped after $2732 \mathrm{~s}$ due to a syringe pump error. 


\begin{tabular}{|c|c|c|c|c|c|c|}
\hline Fitted values & $\boldsymbol{d}_{\mathbf{1}}$ [nm] & $\boldsymbol{\xi}_{\mathbf{1}}[\mathrm{nm}]$ & $\boldsymbol{d}_{\mathbf{2}}[\mathrm{nm}]$ & $\boldsymbol{\xi}_{\mathbf{2}}$ [nm] & $\boldsymbol{d}_{\mathbf{3}}$ [nm] & $\boldsymbol{\xi}_{\mathbf{3}}$ [nm] \\
\hline EH-IDTBR 12s & 12.2 & 4.7 & 41 & 22 & 562 & 20 \\
\hline EH-IDTBR 3s & 12.0 & 5.0 & 41 & 17 & 225 & 18 \\
\hline O-IDTBR 12s & 12.4 & 4.8 & 34 & 32 & 489 & 16 \\
\hline O-IDTBR 3s & 12.5 & 3.9 & 30 & 18 & 241 & 13 \\
\hline
\end{tabular}

Table 3: Fitted values from the four experiments. All units of [nm].

\begin{tabular}{|c|c|c|c|c|c|c|}
\hline Errors & $d_{1}[\mathrm{~nm}]$ & $\xi_{1}[\mathrm{~nm}]$ & $d_{2}[\mathrm{~nm}]$ & $\xi_{2}[\mathrm{~nm}]$ & $d_{3}[\mathrm{~nm}]$ & $\xi_{3}[\mathrm{~nm}]$ \\
\hline EH-IDTBR 12s & 1.4 & 0.2 & 10 & 3.2 & 11.1 & 1.7 \\
\hline EH-IDTBR 3s & 1.7 & 0.4 & 14 & 2.1 & 10.3 & 1.9 \\
\hline O-IDTBR 12s & 2.1 & 0.3 & 3.5 & 2.7 & 9.2 & 1.5 \\
\hline O-IDTBR 3s & 2.2 & 0.4 & 12.0 & 1.3 & 4.1 & 0.6 \\
\hline
\end{tabular}

Table 4: Standard deviations of the fitted values from the four experiments. All units of [nm].

\section{Discussion}

The incidence angle is very important for a GISAXS experiment. It can be questioned how stable the film will move with respect to the incidence angle during roll-to-roll coating of 18 meters film on a flexible substrate. For the experiments performed in this demonstration, we cannot prove the stability of the moving substrate, but previous published data where an older version of the setup is used, document a stable film ${ }^{18,21}$. Previous synchrotron experiments where this rollto-roll coater has been used have demonstrated that the incidence angle does not vary more than $\pm 0.03^{\circ}$ as evaluated by the position of the reflected beam as a function of time (with a temporal resolution of $0.1 \mathrm{~s}$ ), which is equal to \pm 12 pixels from the Yoneda line for this experiment, whereas, the horizontal line integration were made with \pm 50 pixels. Under the assumption made for this analysis, this small change of incidence angle will not influence the analysis of this work and can therefore be neglected. In the future, this type of experiments should be performed without a beam-stop and with continuous collection of data to probe the angle of incidence throughout the experiment.

Air convection above the drying film, relative pressure, and relative humidity are known to influence the dryingprofile of thin-films; thus, to make a fully reproducible experiment, carefully measuring these parameters is a necessity. Comparison between the four measurements in this paper is valid due to the fact that these were coated under the exact same conditions on the same day.

To perform a roll-to-roll in situ GISAXS experiment, several criteria must be fulfilled to ensure a successful experiment. The differences in electron density (contrast) between the materials need to be high enough in order to have a scattering 
signal. Guidelines on this topic have been published J. AlsNielsen et al. ${ }^{53}$.

Due to the low X-ray flux of a laboratory source relative to a synchrotron, much more material is needed to perform such experiments. Thus, it is not fully applicable for materials discovery but will serve as a tool for optimization of formulations of inks relevant for OPVs. Additionally, due to the low flux, it is only possible to perform coarser experiments with respect to the temporal resolution of drying inks. During such experiments we are probing 18 meters of active layer while drying. We expect small variations in the large-scale morphology throughout the experiment, and we therefore probe the mean of 18 meters of coated film. This mimics the conditions of a large scale fabrication. If the inhomogeneity within a few meters are to be studied, synchrotron radiation is needed.

Performing exposures of 3000 seconds is not the optimal experimental design. A more robust method is to perform several shorter exposures to allow flexible temporal binning of data to analyze the large scale homogeneities and to probe the incidence angle at all times.

To the best of our knowledge, this is the first demonstration of performing an in situ GISAXS on roll-to-roll coating of inks for OPVs on a laboratory X-ray source, although we have previously demonstrated similar experiments analyzing the crystalline diffraction signal ${ }^{54,55}$. With this demonstration and protocol, we believe it will be easier to apply and perform in situ GISAXS experiments for researchers, students, and developing engineers. This can potentially accelerate the research field, simply because it is possible to access such equipment on a day-to-day basis. Additionally, by using a roll-to-roll coater it is possible to compare the solar cell performance with the structural properties probed in this experiment, 1:1.

Improvements of the experimental setup are required to exploit all the advantages of having an in house X-ray source. Besides increasing the usable X-ray flux for small laboratory sources, the first step for the improvement of this experiment is to avoid scattering peaks from aluminum that are overlying the data, as shown in Figure 9 (left). This can be realized by installing an X-ray absorbing substrate holder that can withstand temperatures up to $150{ }^{\circ} \mathrm{C}$ for proper heating. Additionally, guard slits just before the sample will improve the data quality. This demonstration is not exclusively of interest for research in the organic solar cell community, but any field that is researching or optimizing coating parameters for thin-film technologies. Combining this technique with simultaneous GIWAXS, where crystalline structures are probed, will further increase the number of the scientific fields where in house roll-to-roll X-ray experiments are applicable.

As these in situ roll-to-roll experiments are probing wet films, it is beneficial if the solvent is not absorbing too large fractions of the illuminated X-ray beam. In general polymer:PCBM systems have a large contrast and combined with a solvent that does not contain chlorine (which is a strong X-ray absorber) will guarantee a large contrast, thus a high scattering intensity. For this experiment, the contrast of P3HT:IDTBR is small and combined with a chlorinated solvent the scattering intensity is low. These materials are not ideal for such an experiment, but very interesting for solar cells, which is why this technique must be further developed to ensure that systems with low contrast and high absorbance can be probed as well. The choice of model is the most determining factor to perform a comparative 
analysis across several GISAXS experiments. For the analysis presented in this paper, the framework of TeubnerStrey was applied to describe the four data sets. The best method to choose a model is to possess ab initio information about the shape and size of the investigated sample. This can be achieved from either TEM images, simulations, or microscope pictures. The reasoning behind our choice of model is stated in the text, but it should be noted that several models can be chosen for describing such GISAXS data. The Teubner-Strey model was originally developed for transmission SAXS but have successfully modelled GIWAXS data of $\mathrm{BHJ}$ solar cells before ${ }^{51}$ and now here. Further improvements are to adapt abstract geometric models as known from molecular dynamics simulations and apply DWBA to model 2D data. Alternative models include: strict geometrical objects with a degree of polydisperse distribution of size as described and applied in ${ }^{53}$, where the DWBA is necessary to model $2 \mathrm{D}$ data, a combination of Fresnel reflectivity and Gaussian distributions to fit ordered systems as co-block polymers GISAXS signals ${ }^{56}$, bead models mainly for biological samples 57 , and fractal geometry 58,59 .

\section{Disclosures}

The authors have nothing to disclose.

\section{Acknowledgments}

The authors would like to acknowledge the two technicians who helped rebuilding and maintaining the instrument, Kristian Larsen and Mike Wichmann. Furthermore, the authors would like to thank Roar R. Søndergaard and Anders Skovbo Gertsen for fruitful discussions. This study was supported by the European Research Council (ERC) under the European Union's Horizon 2020 research and innovation programme (SEEWHI Consolidator grant No. ERC-2015CoG-681881).

\section{References}

1. Krebs, F.C., Espinosa, N., Hösel, M., Søndergaard, R.R., Jørgensen, M. 25th Anniversary Article: Rise to Power - OPV-Based Solar Parks. Advanced Materials. 26 (1), 29-39 (2014).

2. Søndergaard, R., Hösel, M., Angmo, D., Larsen-Olsen, T.T., Krebs, F.C. Roll-to-roll fabrication of polymer solar cells. Materials Today. 15 (1-2), 36-49 (2012).

3. Lucera, L. et al. Guidelines for Closing the Efficiency Gap between Hero Solar Cells and Roll-To-Roll Printed Modules. Energy Technology. 3 (4), 373-384 (2015).

4. Gu, X. et al. Roll-to-Roll Printed Large-Area AllPolymer Solar Cells with 5\% Efficiency Based on a Low Crystallinity Conjugated Polymer Blend. Advanced Energy Materials. 7 (14), 1602742 (2017).

5. Ding, Z., Stoichkov, V., Horie, M., Brousseau, E., Kettle, J. Spray coated silver nanowires as transparent electrodes in OPVs for Building Integrated Photovoltaics applications. Solar Energy Materials and Solar Cells. 157, 305-311 (2016).

6. Few, S., Frost, J.M., Nelson, J. Models of charge pair generation in organic solar cells. Physical Chemistry Chemical Physics. 17 (4), 2311-2325 (2015).

7. Alessandri, R., Uusitalo, J.J., De Vries, A.H., Havenith, R.W.A., Marrink, S.J. Bulk Heterojunction Morphologies with Atomistic Resolution from Coarse-Grain Solvent Evaporation Simulations. Journal of the American Chemical Society. 139 (10), 3697-3705 (2017). 
8. Mirsafaei, M. et al. The influence of electrical effects on device performance of organic solar cells with nanostructured electrodes. Scientific Reports. 7 (1) (2017).

9. Liu, Q. et al. $18 \%$ Efficiency organic solar cells. Science Bulletin. (2020).

10. Gertsen, A.S., Castro, M.F., Søndergaard, R.R., Andreasen, J.W. Scalable fabrication of organic solar cells based on non-fullerene acceptors. Flexible and Printed Electronics. 5 (1), 014004 (2020).

11. Holliday, S. et al. High-efficiency and air-stable P3HTbased polymer solar cells with a new non-fullerene acceptor. Nature Communications. 7, 1-11 (2016).

12. Yan, C., Barlow, S., Jen, A.K.Y., Marder, S. Non-fullerene acceptors for organic solar cells High Energy Density Nanocomposites Based on Surface-Modified BaTiO3 and a Ferroelectric Polymer View project Organic Solar Cells View project. Nature Publishing Group. 3, 1-19 (2018).

13. Pascual-San-José, E. et al. Blade coated P3HT:nonfullerene acceptor solar cells: a high-throughput parameter study with a focus on up-scalability. Journal of Materials Chemistry A. 7 (35), 20369-20382 (2019).

14. Strohm, S. et al. P3HT: Non-fullerene acceptor based large area, semi-transparent PV modules with power conversion efficiencies of $5 \%$, processed by industrially scalable methods. Energy and Environmental Science. 11 (8), 2225-2234 (2018).

15. Liu, K. et al. Roll-coating fabrication of flexible organic solar cells: comparison of fullerene and fullerene-free systems †. Journal of Materials Chemistry. C. (3) (2016).
16. He, Z. et al. Enhanced power-conversion efficiency in polymer solar cells using an inverted device structure. Nature Photonics. 6 (9), 591-595 (2012).

17. Andersen, T.R. et al. Scalable, ambient atmosphere roll-to-roll manufacture of encapsulated large area, flexible organic tandem solar cell modules. Energy and Environmental Science. 7 (9), 2925-2933 (2014).

18. Rossander, L.H. et al. In-line, roll-to-roll morphology analysis of organic solar cell active layers. Energy and Environmental Science. 2411-2419 (2017).

19. Müller-Buschbaum, P. A basic introduction to grazing incidence small-angle X-ray scattering. Lecture Notes in Physics. 776, 61-89 (2009).

20. Teubner, M., Strey, R. Origin of the scattering peak in microemulsions. The Journal of Chemical Physics. 87 (5), 3195-3200 (1987).

21. Böttiger, A.P.L., Jorgensen, M., Menzel, A., Krebs, F.C., Andreasen, J.W. High-throughput roll-to-roll Xray characterization of polymer solar cell active layers. Journal of Materials Chemistry. 22 (42), 22501-22509 (2012).

22. Herzog, G. et al. In situ grazing incidence smallangle X-ray scattering investigation of polystyrene nanoparticle spray deposition onto silicon. Langmuir. 29 (36), 11260-11266 (2013).

23. Perlich, J. et al. Pattern formation of colloidal suspensions by dip-coating: An in situ grazing incidence X-ray scattering study. physica status solidi (RRL) Rapid Research Letters. 6 (6), 253-255 (2012).

24. Schwartzkopf, M., Roth, S. Investigating PolymerMetal Interfaces by Grazing Incidence Small-Angle X- 
Ray Scattering from Gradients to Real-Time Studies. Nanomaterials. 6 (12), 239 (2016).

25. Fan, Q. et al. High-Performance As-Cast Nonfullerene Polymer Solar Cells with Thicker Active Layer and Large Area Exceeding 11\% Power Conversion Efficiency. Advanced Materials. 30 (6), 1-7 (2018).

26. Liu, F. et al. Fast printing and in situ morphology observation of organic photovoltaics using slot-die coating. Advanced Materials. 27 (5), 886-891 (2015).

27. Liu, F. et al. Printing Fabrication of Bulk Heterojunction Solar Cells and In Situ Morphology Characterization. Journal of Visualized Experiments. (119), 53710 (2017).

28. Hexemer, A., Müller-Buschbaum, P. Advanced grazingincidence techniques for modern soft-matter materials analysis. IUCrJ. 2 (1), 106-125 (2015).

29. Carlé, J.E., Helgesen, M., Madsen, M. V., Bundgaard, E., Krebs, F.C. Upscaling from single cells to modulesfabrication of vacuum- and ITO-free polymer solar cells on flexible substrates with long lifetime. Journal of Materials Chemistry C. 2 (7), 1290-1297 (2014).

30. Carlé, J.E. et al. Overcoming the Scaling Lag for Polymer Solar Cells. Joule. 1 (2), 274-289 (2017).

31. Dectris Technical Specifications EIGER R 4M Detector Systems. at <www.dectris.com>. (2018).

32. Riekel, C., Burghammer, M., Davies, R., Gebhardt, R., Popov, D. Applications of Synchrotron Light to Scattering and Diffraction in Materials and Life Sciences. Lecture Notes in Physics. 776 (2009), 91-104 (2009).

33. Pauw, B.R. Everything SAXS: Small-angle scattering pattern collection and correction. Journal of Physics Condensed Matter. 25 (38), 1-2 (2013).
34. Babonneau, D. FitGISAXS: Software package for modelling and analysis of GISAXS data using IGOR Pro. Journal of Applied Crystallography. 43 (4), 929-936 (2010).

35. Yoneda, $\mathrm{Y}$. Anomalous surface reflection of $\mathrm{X}$ rays. Physical Review. 131 (5), 2010-2013 (1963).

36. Schwartzkopf, M., Roth, S. V. Investigating polymermetal interfaces by grazing incidence small-angle $\mathrm{x}$ ray scattering from gradients to real-time studies. Nanomaterials. 6 (12) (2016).

37. Liu, J., Yager, K.G. Unwarping GISAXS data. IUCrJ. 5, 737-752 (2018).

38. Benecke, G. et al. A customizable software for fast reduction and analysis of large X-ray scattering data sets: Applications of the new DPDAK package to small-angle X-ray scattering and grazing-incidence small-angle X-ray scattering. Journal of Applied Crystallography. 47 (5), 1797-1803 (2014).

39. Pandolfi, R.J. et al. Xi-cam: a versatile interface for data visualization and analysis. Journal of Synchrotron Radiation. 25 (4), 1261-1270 (2018).

40. Pröller, S. et al. Following the Morphology Formation In Situ in Printed Active Layers for Organic Solar Cells. Advanced Energy Materials. 6 (1), 1501580 (2016).

41. Pedersen, E.B.L. et al. Structure and crystallinity of water dispersible photoactive nanoparticles for organic solar cells. Journal of Materials Chemistry A. 3 (33), 17022-17031 (2015).

42. Liang, Q. et al. Separating Crystallization Process of P3HT and O-IDTBR to Construct Highly Crystalline Interpenetrating Network with Optimized Vertical Phase 
Separation. Advanced Functional Materials. 29 (47), 1807591 (2019).

43. Allen, S.M. Spinodal Decomposition. Encyclopedia of Materials: Science and Technology. 8761-8764 (2001).

44. Schubert, K. V., Strey, R., Kline, S.R., Kaler, E.W. Small angle neutron scattering near Lifshitz lines: Transition from weakly structured mixtures to microemulsions. The Journal of Chemical Physics. 101 (6), 5343-5355 (1994).

45. Gould, H., Tobochnik, J. Statistical and thermal physics : with computer applications. Princeton University Press. (2010).

46. Pospelov, G. et al. BornAgain: software for simulating and fitting grazing-incidence small-angle scattering. Journal of Applied Crystallography. 53, 262-276 (2020).

47. Wienhold, K.S. et al. Effect of Solvent Additives on the Morphology and Device Performance of Printed Nonfullerene Acceptor Based Organic Solar Cells. ACS Applied Materials \& Interfaces. 11 (45), 42313-42321 (2019).

48. Pröller, S. et al. Electrophoresis Assisted Printing: A Method to Control the Morphology in Organic Thin Films. ACS Applied Materials and Interfaces. 12 (5), 5219-5225 (2020).

49. Busch, P., Rauscher, M., Smilgies, D.M., Posselt, D., Papadakis, C.M. Grazing-incidence small-angle X-ray scattering from thin polymer films with lamellar structures - The scattering cross section in the distorted-wave Born approximation. Journal of Applied Crystallography. 39 (3), 433-442 (2006).

50. Busch, P., Posselt, D., Smilgies, D.M., Rauscher, M., Papadakis, C.M. Inner structure of thin films of lamellar poly(styrene-b-butadiene) diblock copolymers as revealed by grazing-incidence small-angle scattering. Macromolecules. 40 (3), 630-640 (2007).

51. Kozub, D.R. et al. Polymer Crystallization of Partially Miscible Polythiophene/Fullerene Mixtures Controls Morphology. Macromolecules. 44, 5722-5726 (2011).

52. Köntges, W. et al. Visualizing morphological principles for efficient photocurrent generation in organic non-fullerene acceptor blends. Energy \& Environmental Science. 1259-1268 (2020).

53. Als-Nielsen, J., McMorrow, D. Elements of Modern Xray Physics: Second Edition. Elements of Modern X-ray Physics: Second Edition. John Wiley and Sons. (2011).

54. Rossander, L.H., Zawacka, N.K., Dam, H.F., Krebs, F.C., Andreasen, J.W. In situ monitoring of structure formation in the active layer of polymer solar cells during roll-to-roll coating. AIP Advances. 4 (8) (2014).

55. Zawacka, N.K. et al. The influence of additives on the morphology and stability of roll-to-roll processed polymer solar cells studied through ex situ and in situ X-ray scattering. Journal of Materials Chemistry A. 2 (43), 18644-18654 (2014).

56. Renaud, G., Lazzari, R., Leroy, F. Probing surface and interface morphology with Grazing Incidence Small Angle X-Ray Scattering. Surface Science Reports. 64 (8), 255-380 (2009).

57. Hajizadeh, N.R., Franke, D., Jeffries, C.M., Svergun, D.I. Consensus Bayesian assessment of protein molecular mass from solution X-ray scattering data. Scientific Reports. 8 (1) (2018).

58. Bale, H.D., Schmidt, P. Small-Angle X-Ray-Scattering Investigation of Submicroscopic Porosity with Fractal Properties. Phys. Rev. Lett. 3 (6) (1984). 
59. Anitas, E.M., Slyamov, A. Structural Properties of Additive Nano/Microcellular Automata. Annalen der Physik. 530 (6), 1800004 (2018). 